\title{
Transcatheter closure of atrial septal communication: impact on P-wave dispersion, duration, and arrhythmia in mid-term follow-up
}

\author{
Maria Lelakowska ${ }^{1}$, Monika Komar ${ }^{2}$, Paweł T. Matusik ${ }^{3}$, Jadwiga Nessler ${ }^{4}$, Piotr Podolec ${ }^{2}$, Maria Olszowska $^{2}$ \\ 'Department of Coronary Disease and Heart Failure, John Paul II Hospital, Krakow, Poland \\ 2Department of Cardiac and Vascular Diseases, Institute of Cardiology, Jagiellonian University Medical College, \\ John Paul II Hospital, Krakow, Poland \\ ${ }^{3}$ Department of Electrocardiology, Institute of Cardiology, Jagiellonian University Medical College, John Paul II Hospital, Krakow, Poland \\ ${ }^{4}$ Department of Coronary Disease and Heart Failure, John Paul II Hospital, Institute of Cardiology, Jagiellonian University Medical College, \\ Krakow, Poland
}

\begin{abstract}
Background: Atrial septal communications (ASCs) include atrial septal defects (ASDs) and patent foramen ovale (PFO).

Aim: The purpose of this study was to assess P-wave dispersion (PWD) and the prevalence of arrhythmia in patients before and after ASC closure.

Methods: We analysed the clinical history and performed 12-lead electrocardiograms, echocardiograms, and 24-h Holter electrocardiograms in patients with ASC, before and six months after ASC closure.

Results: We included patients with ASD $(n=56)$ and PFO $(n=73)$. PWD before percutaneous ASC closure was predicted by right ventricular outflow tract (RVOT) proximal diameter, left atrial area, ASD, smoking, and paroxysmal dyspnoea, $\mathrm{R}^{2}=0.67$; $p<0.001$. RVOT proximal diameter was an independent predictor of PWD, both in patients with ASD and PFO. Six months after successful closure of ASC, a reduction in PWD was observed in the whole group of patients as well as in patients with ASD and PFO considered separately. A decrease in PWD was associated with reduction of maximum P-wave duration. At the same time, in the whole group, we noticed a reduction in the number of supraventricular and ventricular extrasystolic beats and fewer atrial fibrillation (AF) episodes, $\mathrm{p}<0.04$ for all variables. Postprocedural AF episodes in patients with ASD were predicted by PWD of $80 \mathrm{~ms}$.

Conclusions: Percutaneous closure of ASC is associated with a reduction of PWD and fewer arrhythmia episodes six months after the procedure. PWD predicts AF episodes after ASD closure.
\end{abstract}

Key words: atrial septal defect, patent foramen ovale, P-wave dispersion, arrhythmia

Kardiol Pol 2018; 76, 10: 1465-1473

\section{INTRODUCTION}

Atrial septal defects (ASDs) are the most common congenital heart defects in adults, and they comprise about $40 \%$ of congenital heart defects diagnosed in patients over 40 years old. Classification of ASDs is based on its anatomical location and the presence of concomitant anomalies. The risk for development of pulmonary vascular disease with right ventricular insufficiency indicates the necessity for the referral of these patients for closure of the defect. Percutaneous closure with an occluder can only be performed in ostium secundum ASD (ASD II), which is possible in $96 \%$ to $100 \%$ of cases. On the other hand, patent foramen ovale (PFO), a remnant of interatrial communication present in foetal life, is diagnosed in $25 \%$ to $30 \%$ of post-mortem examinations. PFO is a potential space between the septum primum and septum secundum, which may cause right-to-left shunt after changes in pressure gradient between the atria. According to previous observations, the presence of PFO may be associated the occurrence 
of a cryptogenic stroke. Current recommendations advise consideration of PFO closure in case of recurrent cryptogenic stroke despite optimal pharmacotherapy.

Implantation of the occluder is performed under fluoroscopy and transoesophageal or intracardiac echocardiography guidance [1-4].

The electrophysiological mechanisms of atrial arrhythmias in patients with atrial septal communication (ASC), including ASD and PFO, may involve increased P-wave dispersion (PWD). P-wave duration and its dispersion reflect the heterogenous propagation of sinus beats and disturbances of intra- and interatrial conduction [5-11].

The main aims of the study were to determine the factors influencing PWD in patients with ASC and to assess its changes after ASC closure. Additionally, we aimed to evaluate the prevalence of arrhythmia in patients before and after ASC closure.

\section{METHODS}

\section{Patients}

In this prospective study we included patients scheduled for percutaneous closure of ASC (study group).

Patients were included in the study group if they met the following criteria: (1) they were scheduled for percutaneous closure of a single ASD or PFO; (2) their P-waves were easily visible in 12-lead resting electrocardiogram (ECG) and the images obtained by transthoracic echocardiography (TTE) were of good quality.

Exclusion criteria comprised (1) chronic atrial fibrillation (AF); (2) previous cardiac surgery, AF ablation, or cardiovascular implantable electronic device placement; (3) left ventricular ejection fraction (LVEF) below $50 \%$ or dementia; (4) the presence of significant leaking around the implanted occluder; (5) the presence of significant valvular heart disease and/or other congenital cardiovascular defect; (6) cardiomyopathy; and (7) non-echogenicity (difficult-to-interpret echocardiography imaging) and/or poor visibility of P-waves in ECG.

\section{Clinical assessment}

All patients provided their clinical history and underwent clinical examination. Structural cardiovascular abnormalities, and comorbidities were diagnosed on the basis of commonly accepted standards. ASD and PFO were diagnosed after clinical assessment, TTE, and transoesophageal echocardiography (TEE), which were also used to identify patients eligible for percutaneous ASC closure. Diagnosis and eligibility for the procedure were confirmed during cardiac catheterisation immediately before implantation of the occluder.

\section{2-lead resting ECG}

Electrocardiogram was recorded at a speed of $50 \mathrm{~mm} / \mathrm{s}$, with augmentation of $1 \mathrm{~cm}=1 \mathrm{mV}$. P-wave duration was assessed in five consecutive sinus beats. In each ECG lead the P-wave was manually assessed with a standard ECG ruler, with accuracy up to $10 \mathrm{~ms}$. P-wave duration was defined as the distance from the beginning (positive or negative deflection from the isoelectric line) to its end (return to the isoelectric line), using $4 \times$ magnification of the image. Maximum and minimum P-wave durations were determined. PWD was defined as the difference between the maximum and minimum P-wave duration in a 12-lead resting ECG. The mean PWD value was calculated from five consecutive measurements and was rounded to full values. The abovementioned parameters were measured by an experienced investigator who was blinded to the patients' characteristics. At the time of measurements, the patients were not taking any medications affecting intra- and interatrial conduction $[10,11]$.

\section{4-h Holter ECG monitoring, TTE, and TEE}

Recording of the 24-h Holter ECG monitoring was performed using a three-channel DelMar Avionics model 563 (Reynolds, Irvine, CA, USA) device. Analyses of the recordings were done with DelMar Avionics (Reynolds, Irvine, CA, USA) software, and the following were determined: mean, minimum and maximum heart rate $(H R)$ and the presence of supraventricular extrasystolic beats (SVEB), ventricular extrasystolic beats (VEB), and AF episodes [12-14]. AF was defined as an episode of AF lasting at least $30 \mathrm{~s}$ during 24-h Holter ECG monitoring. Echocardiography was performed according to guideline recommendations [15-17] using a Toshiba Power Vision model 7000 (Toshiba, Otawara, Japan) ultrasound system and ultrasound probes with a frequency of 2.5 to 3.5 MHz. It included M-mode imaging, two-dimensional (2D) imaging, pulse wave Doppler, continuous wave Doppler, and colour flow Doppler imaging. Assessment of ASC size and location was performed in 2D mode on the basis of standard views. During TEE, morphology of atrial septum was assessed in bicaval view and high longitudinal view. Enlarged left atrium (LA) was defined as LA area over $20 \mathrm{~cm}^{2}$, while enlarged right atrium (RA) was defined as RA area over $17 \mathrm{~cm}^{2}$.

All measurements were performed before percutaneous closure of ASD or PFO and six months after the procedure. The study was in accordance with ethical standards, and all patients gave written consent to undergo the studies and procedure according to Polish/European Society of Cardiology standards.

\section{Statistical analysis}

Quantitative variables were presented as the mean \pm standard deviation, median, range, and/or interquartile range (IQR). Qualitative variables were presented as number and/or frequency. The Shapiro-Wilk test was used to verify the normality of distribution for quantitative variables. Student $t$ test or Mann-Whitney $U$ test was used to assess the associations of qualitative variables between patients with ASD and PFO. Verification of the relationship between two qualitative 
variables was performed with the $\chi^{2}$ test or Fisher exact test. Analysis of changes in quantitative variables, before and after the procedure, was performed using Wilcoxon matched-pairs test, and in the qualitative (dichotomous) variables with McNemar's test for repeated measures. The strength of the relationship between two quantitative variables was assessed using the Spearman correlation coefficient $\left(r_{s}\right)$. A p-value of $<0.05$ was assumed as significant.

Selected variables associated with PWD $(p<0.05)$ in univariate analysis, which did not substantially correlate (including correlation coefficient $\geq 0.6$ ) with other independent variables, were included into multiple linear regression analyses. The selection of variables that significantly influenced the dependent variable was performed using the stepwise backward regression. $\mathrm{R}^{2}$ was calculated, and assessment of model adequacy was measured using $\mathrm{F}_{\mathrm{k}, \mathrm{n}-\mathrm{k}-1}$ test, where $k$ is a number of variables in a model, and $n$ is a number of patients in a group.

To determine the cut-off point of PWD for the presence of AF or SVEB after the procedure, receiver operating characteristic (ROC) curves were drawn. Positive thresholds were determined using the Youden index. Statistical analyses were performed with STATISTICA 12 (StatSoft, Tulsa, OK, USA) or IBM SPSS Statistics (version 24, IBM Corp., Armonk, NY, USA, for multiple regression analysis).

\section{RESULTS}

\section{Patient characteristics}

We included 129 patients (59 men) aged from 19 to 76 years (mean age $44.5 \pm 13.4$ years) referred for percutaneous closure of ASD $(n=56)$ or PFO $(n=73)$. Patients with ASD were older $(p<0.001)$ and more often female $(p<0.001)$ than patients with PFO.

The clinical characteristics of the studied patients are shown in Table 1.

\section{$A S D, P F O$, and procedural characteristics}

The mean resting size of ASD was $11.6 \pm 5.9 \mathrm{~mm}$ (range $3.4-24 \mathrm{~mm}$ ), while the size after dilatation with a diagnostic catheter was $20.3 \pm 6.6 \mathrm{~mm}$ (range 7.1-30.9 mm). Mean size of PFO was $9.1 \pm 3.1 \mathrm{~mm}$ (range 3-15.4 mm), while separation of the septum primum and secundum after contrast administration was $3.6 \pm 1.6 \mathrm{~mm}$ (range $2-8.9 \mathrm{~mm}$ ). Closure of ASC was performed with occluders with a mean size of $25 \pm 4.9 \mathrm{~mm}$ (range $7-34 \mathrm{~mm}$ ). Mean fluoroscopy time was $7 \pm 4.8 \mathrm{~min}$ (range 2.4 to $17 \mathrm{~min}$ ), while mean radiation absorbed dose was $76.4 \pm 135 \mathrm{mGy}$ (range 5 to $580 \mathrm{mGy}$ ).

\section{Associations with PWD and related variables}

P-wave dispersion correlated with several clinical, echocardiographic (including left and right atrial areas as well as right ventricular dimensions), and interestingly also with procedure-related parameters (Table 2). PWD in ASC was predicted by right ventricular outflow tract (RVOT) proximal diameter (unstandardised coefficient B: 0.78; 95\% confidence interval $[\mathrm{Cl}]$ 0.47-1.08), LA area (B: 1.03; 95\% Cl 0.56-1.50), ASD (B: 8.67; 95\% Cl 3.21-14.13), smoking (B: 11.93; 95\% $\mathrm{Cl}$ 5.69-18.17), and paroxysmal dyspnoea (B: 6.84; 95\% Cl 0.06-13.62), $\mathrm{R}^{2}=0.67 ; \mathrm{p}<0.001$ (Table 3). Detailed analysis of PWD predictors in patients with ASD and PFO is shown in Table 3.

The procedure was associated with significant reduction in PWD in patients with ASD $(61.6 \pm 17.1 \mathrm{~ms}$ vs. $35.8 \pm 22.0 \mathrm{~ms} ; \mathrm{p}<0.001)$ and PFO $(36.7 \pm 18.6 \mathrm{~ms}$ vs. $18.1 \pm 9.7 \mathrm{~ms} ; \mathrm{p}<0.001 ;$ Table 4 ). It was related to reduction of maximum $\mathrm{P}$-wave duration also in patients with ASD $(134 \pm 11.4 \mathrm{~ms}$ vs. $107 \pm 18.6 \mathrm{~ms} ; \mathrm{p}<0.001)$ and PFO $(111 \pm 15.5 \mathrm{~ms}$ vs. $91.7 \pm 14.6 \mathrm{~ms} ; \mathrm{p}<0.001)$. On the other hand, minimum P-wave duration did not differ before the procedure and at six-month follow-up (Table 4).

\section{Results of Holter monitoring and prevalence of arrhythmia}

After the procedure maximum, minimum, and mean Holter-derived HR decreased in the whole study group and in the group of ASD patients, while in patients with PFO a decrease was observed only in maximum HR (Table 4).

In the whole study group the numbers of SVEBs and VEBs before the procedure were 54.0 (4.0-242.0)/day and $1.0(0.0-6.0) /$ day, respectively.

The number of SVEBs ( $p<0.001$ for patients with ASD and PFO analysed together and separately) and VEBs ( $p=0.038$ for all patients who underwent a successful procedure) was lower after percutaneous closure of ASC. On the other hand, in patients with ASD or PFO considered separately the number of VEBs did not change $(p=0.145$ and $p=0.156$, respectively). The percentages of patients with extrasystolic beats reduced by a factor of approximately two (SVEB: $83 \%$ vs. $43 \%, p<0.001$; VEB: $63 \%$ vs. $38 \%$, p < 0.001). After the procedure patients with ASD and PFO did not differ with regards to SVEB number (median [IQR]: 4 [0-349] vs. 0 [0-10] $\mathrm{SVEB} /$ day, $\mathrm{p}=0.182$ ). In patients in whom arrhythmias persisted, their intensity according to VEB $(p=0.466)$ and SVEB $(p=0.37)$ did not change. AF episodes were observed in 25 (19.4\%) patients (18 patients with ASD and seven patients with PFO) before the procedure and in seven (5.4\%) patients (all with ASD) after ASC closure $(p<0.001)$ during 24-h Holter ECG monitoring. In patients with AF, PWD before and after the procedure was $70.4 \pm 11.5 \mathrm{~ms}$ and $48.7 \pm 23.0 \mathrm{~ms}$ $(p<0.001)$, respectively, while in patients without AF it was $42.1 \pm 20.4 \mathrm{~ms}$ and $20.8 \pm 12.6 \mathrm{~ms}(\mathrm{p}<0.001)$. In patients with $\mathrm{AF}$, maximum P-wave duration before and after the procedure was $135.7 \pm 9.5 \mathrm{~ms}$ and $115.7 \pm 21.1 \mathrm{~ms}$ $(p<0.001)$, respectively, while in patients without AF it was $117.5 \pm 17.7 \mathrm{~ms}$ and $94.7 \pm 15.0 \mathrm{~ms}(\mathrm{p}<0.001)$. ROC curve has shown $80 \mathrm{~ms}$ as a cut-off point of PWD 
Table 1. Clinical characteristics of patients undergoing closure of atrial septal communication

\begin{tabular}{|c|c|c|c|}
\hline Variable & $\operatorname{ASD}(n=56)$ & PFO $(n=73)$ & $\mathbf{p}$ \\
\hline Age [years] & $49.8 \pm 13.3$ & $40.5 \pm 12.0$ & $<0.001$ \\
\hline Male sex & $12(21.3)$ & $47(64.4)$ & $<0.001$ \\
\hline \multicolumn{4}{|l|}{ Comorbidities and CVD risk factors: } \\
\hline Arterial hypertension & $17(30.4)$ & $3(4.1)$ & $<0.001$ \\
\hline Pulmonary hypertension & $19(33.9)$ & $0(0.0)$ & $<0.001$ \\
\hline Hyperlipidaemia & $15(26.8)$ & $7(9.6)$ & 0.004 \\
\hline Diabetes mellitus & $4(7.1)$ & $1(1.4)$ & 0.001 \\
\hline Obesity & $3(5.4)$ & $2(2.7)$ & 0.401 \\
\hline Smoking & $14(25.0)$ & $9(12.3)$ & 0.033 \\
\hline Anaemia & $0(0.0)$ & $1(1.4)$ & 0.999 \\
\hline Migraine & $0(0.0)$ & $11(15.1)$ & 0.003 \\
\hline Vasovagal syndrome & $1(1.8)$ & $3(4.1)$ & 0.643 \\
\hline Stroke/TIA & $4(7.1)$ & $24(32.9)$ & $<0.001$ \\
\hline Atrial fibrillation & $17(30.4)$ & $8(11.0)$ & $<0.001$ \\
\hline \multicolumn{4}{|l|}{ Electrocardiographic parameters: } \\
\hline Maximum HR [bpm] & $123.7 \pm 11.0$ & $123.5 \pm 13.4$ & 0.718 \\
\hline Minimum HR [bpm] & $52.0 \pm 6.4$ & $47.7 \pm 6.0$ & $<0.001$ \\
\hline Mean HR [bpm] & $73.3 \pm 6.3$ & $69.4 \pm 5.7$ & 0.001 \\
\hline SVEBs [beats per day] & $748.6 \pm 2127$ & $147.2 \pm 505.1$ & $<0.001$ \\
\hline VEBs [beats per day] & $252.3 \pm 1734$ & $70.2 \pm 331$ & 0.017 \\
\hline Maximum P-wave duration [ms] & $133.9 \pm 11.5$ & $110.8 \pm 15.6$ & $<0.001$ \\
\hline Minimum P-wave duration [ms] & $73.0 \pm 9.9$ & $73.4 \pm 12.7$ & 0.631 \\
\hline P-wave dispersion [ms] & $60.9 \pm 18$ & $37.3 \pm 18.7$ & $<0.001$ \\
\hline \multicolumn{4}{|l|}{ Echocardiographic parameters: } \\
\hline Left-to-right shunt & $54(96.4)$ & $41(56.2)$ & $<0.001$ \\
\hline Interatrial septal aneurysm & $11(19.6)$ & $50(68.5)$ & $<0.001$ \\
\hline Enlarged LA & $35(62.5)$ & $14(19.1)$ & $<0.001$ \\
\hline Enlarged RA & $37(66.1)$ & $14(19.2)$ & $<0.001$ \\
\hline Enlarged right ventricle & $33(58.9)$ & $16(20.6)$ & $<0.001$ \\
\hline Myocardial hypertrophy & $9(16.1)$ & $4(5.5)$ & 0.007 \\
\hline \multicolumn{4}{|l|}{ Device: } \\
\hline Cardia Ultrasept ASD occluder & $4(7.1)$ & $0(0.0)$ & - \\
\hline Cardia Ultrasept PFO occluder & $0(0.0)$ & $69(94.5)$ & - \\
\hline Memopart ASD occluder & $51(91.1)$ & $0(0.0)$ & - \\
\hline No implanted device & $1(1.8)$ & $4(5.5)$ & - \\
\hline \multicolumn{4}{|l|}{ Procedure: } \\
\hline Without complications & $55(98.2)$ & $69(94.5)$ & \\
\hline Stopped due to complications & $0(0.0)$ & $1(1.4)$ & NS \\
\hline Unsuccessful & $1(1.8)$ & $3(4.1)$ & \\
\hline \multicolumn{4}{|l|}{ Medications: } \\
\hline $\mathrm{CCB}$ & $18(32.1)$ & $1(1.4)$ & $<0.001$ \\
\hline$\beta$-blocker & $17(30.4)$ & $10(13.7)$ & 0.015 \\
\hline ACEI & $17(30.4)$ & $5(6.8)$ & $<0.001$ \\
\hline
\end{tabular}

Data are presented as mean \pm standard deviation or number (percentage). ACEI - angiotensin converting enzyme inhibitor; ASD — atrial septal defect; CCB - calcium channel blocker; CVD — cardiovascular disease; HR — heart rate; LA — left atrium; NS — non-significant; PFO — patent foramen ovale; RA — right atrium; SVEB — supraventricular extrasystolic beat; TIA — transient ischaemic attack; VEB — ventricular extrasystolic beat 
Table 2. Spearman correlations $\left(r_{s}\right)$ between quantitative variables and maximum P-wave duration and P-wave dispersion before closure of atrial septal communication

\begin{tabular}{|c|c|c|c|c|c|c|}
\hline \multirow[t]{2}{*}{ Variables $(n=124)$} & \multicolumn{3}{|c|}{ Maximum P-wave duration $r_{s}$ ( $p$-value) } & \multicolumn{3}{|c|}{ P-wave dispersion $r_{s}$ ( $p$-value) } \\
\hline & ASC & ASD & PFO & ASC & ASD & PFO \\
\hline Age [years] & $0.22(0.017)$ & $0.39(0.003)$ & $-0.23(0.047)$ & $0.22(0.016)$ & $0.46(<0.001)$ & $-0.14(0.239)$ \\
\hline NYHA class & $0.29(0.001)$ & $0.12(0.384)$ & $0.21(0.076)$ & $0.30(0.001)$ & $0.17(0.211)$ & $0.23(0.047)$ \\
\hline P-wave dispersion [ms] & $0.88(<0.001)$ & $0.92(<0.001)$ & $0.67(<0.001)$ & - & - & - \\
\hline Minimum HR [bpm] & $0.39(<0.001)$ & $0.31(0.019)$ & $0.23(0.046)$ & $0.33(<0.001)$ & $0.21(0.122)$ & $0.22(0.065)$ \\
\hline \multicolumn{7}{|l|}{ Echocardiography: } \\
\hline RVOT prox. [mm] & $0.47(<0.001)$ & $0.41(0.002)$ & $0.22(0.057)$ & $0.59(<0.001)$ & $0.48(<0.001)$ & $0.42(<0.001)$ \\
\hline TAPSE $[\mathrm{mm}]$ & $0.28(0.002)$ & $0.26(0.052)$ & $0.21(0.075)$ & $0.22(0.016)$ & $0.24(0.069)$ & $0.09(0.473)$ \\
\hline RVD1 [mm] & $0.53(<0.001)$ & $0.50(<0.001)$ & $0.27(0.022)$ & $0.52(<0.001)$ & $0.50(<0.001)$ & $0.19(0.102)$ \\
\hline $\mathrm{RVD} 2[\mathrm{~mm}]$ & $0.57(<0.001)$ & $0.27(0.043)$ & $0.50(<0.001)$ & $0.58(<0.001)$ & $0.33(0.014)$ & $0.51(<0.001)$ \\
\hline RVD3 [mm] & $0.44(<0.001)$ & $0.30(0.027)$ & $0.20(0.089)$ & $0.43(<0.001)$ & $0.30(0.023)$ & $0.19(0.112)$ \\
\hline LA area $\left[\mathrm{cm}^{2}\right]$ & $0.60(<0.001)$ & $0.73(<0.001)$ & $0.13(0.273)$ & $0.69(<0.001)$ & $0.75(<0.001)$ & $0.33(0.005)$ \\
\hline RA area $\left[\mathrm{cm}^{2}\right]$ & $0.63(<0.001)$ & $0.67(<0.001)$ & $0.23(0.052)$ & $0.63(<0.001)$ & $0.74(<0.001)$ & $0.24(0.042)$ \\
\hline $\operatorname{LVSD}[\mathrm{mm}]$ & $-0.31(<0.001)$ & $0.07(0.589)$ & $0.08(0.491)$ & $-0.25(0.005)$ & $0.16(0.231)$ & $-0.03(0.820)$ \\
\hline Qp/Qs ratio & $0.70(<0.001)$ & $0.38(0.003)$ & * & $0.61(<0.001)$ & $0.56(<0.001)$ & * \\
\hline \multicolumn{7}{|l|}{ Procedure: } \\
\hline Fluoroscopy time [min] & $0.46(<0.001)$ & $0.31(0.022)$ & $0.30(0.010)$ & $0.42(<0.001)$ & $0.35(0.008)$ & $0.24(0.039)$ \\
\hline RAD [mGy] & $0.51(<0.001)$ & $0.38(0.004)$ & $0.39(0.001)$ & $0.55(<0.001)$ & $0.38(0.004)$ & $0.52(<0.001)$ \\
\hline
\end{tabular}

ASC — atrial septal communication; HR — heart rate; NYHA — New York Heart Association; RAD — radiation absorbed dose; RVOT prox. — proximal right ventricular outflow tract; TAPSE — tricuspid annular plane systolic excursion; RVD1 — basal right ventricular linear dimension; RVD2 - mid-cavity right ventricular linear dimension; RVD3 — right ventricular longitudinal dimension; LVSD — left ventricular systolic dimension; $\mathrm{Qp} / \mathrm{Qs}$ ratio — pulmonary-to-systemic blood flow ratio; *Qp/Qs ratio = one in all patients

Table 3. Multiple regression analysis of predictors of P-wave dispersion before the procedure in patients with atrial septal communication

\begin{tabular}{|c|c|c|c|c|}
\hline & $\begin{array}{c}\text { Standardised } \\
\text { coefficient } \\
\text { Beta }\end{array}$ & $\begin{array}{c}\text { Unstandardised } \\
\text { coefficient B }\end{array}$ & $\begin{array}{l}95 \% \text { confidence } \\
\text { interval for B }\end{array}$ & p \\
\hline \multicolumn{5}{|c|}{$\operatorname{ASC}\left(R^{2}=0.67 ; F_{5,123}=49.46 ; p<0.001\right)$} \\
\hline RVOT prox. [mm] & 0.32 & 0.78 & $0.47-1.08$ & $<0.001$ \\
\hline Left atrial area $\left[\mathrm{cm}^{2}\right]$ & 0.32 & 1.03 & $0.56-1.50$ & $<0.001$ \\
\hline ASD & 0.20 & 8.67 & $3.21-14.13$ & 0.002 \\
\hline Smoking & 0.21 & 11.93 & $5.69-18.17$ & $<0.001$ \\
\hline Paroxysmal dyspnoea & 0.12 & 6.84 & $0.06-13.62$ & $<0.05$ \\
\hline \multicolumn{5}{|c|}{$\operatorname{ASD}\left(R^{2}=0.59 ; F_{2,53}=38.83 ; p<0.001\right)$} \\
\hline RVOT prox. [mm] & 0.28 & 0.52 & $0.18-0.86$ & 0.003 \\
\hline Left atrial area $\left[\mathrm{cm}^{2}\right]$ & 0.64 & 1.48 & $1.06-1.90$ & $<0.001$ \\
\hline \multicolumn{5}{|c|}{ PFO $\left(R^{2}=0.56 ; F_{3,69}=28.98 ; p<0.001\right)$} \\
\hline RVOT prox. [mm] & 0.48 & 1.28 & $0.83-1.72$ & $<0.001$ \\
\hline Smoking & 0.29 & 16.29 & $6.97-25.61$ & $<0.001$ \\
\hline Tricuspid insufficiency & 0.41 & 17.29 & $10.54-24.03$ & $<0.001$ \\
\hline
\end{tabular}

Abbreviations - see Tables 1 and 2 
Table 4. Changes in selected electrocardiographic parameters before and six months after a successful closure of atrial septal communication

\begin{tabular}{|c|c|c|c|c|c|c|}
\hline & Before & 6-m FU & Before & 6-m FU & Before & 6-m FU \\
\hline ASC & \multicolumn{2}{|c|}{ Max HR [bpm] } & \multicolumn{2}{|c|}{ Min HR [bpm] } & \multicolumn{2}{|c|}{ Mean HR [bpm] } \\
\hline Mean & 123.6 & 118.9 & 49.6 & 45.9 & 71.1 & 67.8 \\
\hline SD & 12.3 & 10.8 & 6.5 & 5.5 & 6.2 & 5.1 \\
\hline $\mathrm{p}$ & \multicolumn{2}{|c|}{$<0.001$} & \multicolumn{2}{|c|}{$<0.001$} & \multicolumn{2}{|c|}{$<0.001$} \\
\hline ASC & \multicolumn{2}{|c|}{ Max P-wave duration [ms] } & \multicolumn{2}{|c|}{ Min P-wave duration [ms] } & \multicolumn{2}{|c|}{ P-wave dispersion [ms] } \\
\hline Mean & 120.9 & 98.5 & 73.3 & 72.6 & 47.5 & 25.6 \\
\hline SD & 18.1 & 18.2 & 11.5 & 9.9 & 21.8 & 18.5 \\
\hline $\mathrm{p}$ & \multicolumn{2}{|c|}{$<0.001$} & \multicolumn{2}{|c|}{ NS } & \multicolumn{2}{|c|}{$<0.001$} \\
\hline ASD & \multicolumn{2}{|c|}{ Max HR [bpm] } & \multicolumn{2}{|c|}{ Min HR [bpm] } & \multicolumn{2}{|c|}{ Mean HR [bpm] } \\
\hline Mean & 123.7 & 113.6 & 52.0 & 44.0 & 73.3 & 66.2 \\
\hline SD & 11.0 & 9.3 & 6.4 & 4.5 & 6.3 & 5.3 \\
\hline $\mathrm{p}$ & \multicolumn{2}{|c|}{$<0.001$} & \multicolumn{2}{|c|}{$<0.001$} & \multicolumn{2}{|c|}{$<0.001$} \\
\hline ASD & \multicolumn{2}{|c|}{ Max P-wave duration [ms] } & \multicolumn{2}{|c|}{ Min P-wave duration [ms] } & \multicolumn{2}{|c|}{ P-wave dispersion [ms] } \\
\hline Mean & 133.9 & 106.9 & 73.0 & 71.6 & 60.9 & 35.3 \\
\hline SD & 11.5 & 18.5 & 9.9 & 8.6 & 18.0 & 22.0 \\
\hline $\mathrm{p}$ & \multicolumn{2}{|c|}{$<0.001$} & \multicolumn{2}{|c|}{0.218} & \multicolumn{2}{|c|}{$<0.001$} \\
\hline PFO & \multicolumn{2}{|c|}{ Max HR [bpm] } & \multicolumn{2}{|c|}{ Min HR [bpm] } & \multicolumn{2}{|c|}{ Mean HR [bpm] } \\
\hline Mean & 123.5 & 123.1 & 47.7 & 47.4 & 69.4 & 69.1 \\
\hline SD & 13.4 & 10.0 & 6.0 & 5.7 & 5.7 & 4.5 \\
\hline $\mathrm{p}$ & \multicolumn{2}{|c|}{0.04} & \multicolumn{2}{|c|}{0.992} & \multicolumn{2}{|c|}{0.816} \\
\hline PFO & \multicolumn{2}{|c|}{ Max P-wave duration [ms] } & \multicolumn{2}{|c|}{ Min P-wave duration [ms] } & \multicolumn{2}{|c|}{ P-wave dispersion [ms] } \\
\hline Mean & 110.8 & 91.9 & 73.4 & 73.3 & 37.3 & 18.6 \\
\hline SD & 15.6 & 14.9 & 12.7 & 10.8 & 18.7 & 10.5 \\
\hline $\mathrm{p}$ & & & & & & \\
\hline
\end{tabular}

Data are presented as means and standard deviations. 6-m FU — six-month follow-up; max — maximum; min — minimum; NS — non-significant; for other abbreviations see Table 1 and 2

before the procedure for the presence of an AF episode six months after successful closure of ASC (Fig. 1A) (area under the curve $[\mathrm{A \cup C}]=0.949$; sensitivity $=85.7 \%$; specificity $=93.2 \% ; p<0.001)$. The same cut-off point was determined for patients with ASD considered separately (Fig. 1B) $(\mathrm{AUC}=0.885$; sensitivity $=85.7 \%$; specificity $=83.3 \%$; $p<0.001)$. ROC curve of PWD before the procedure for the presence of SVEBs six months after successful closure of ASC is shown in Figure 1C (AUC $=0.641$; sensitivity $=58.9 \%$; specificity $=64.7 \% ; p=0.005)$. There were no AF episodes observed after PFO closure. ROCs for the prediction of SVEB after ASD or PFO closure, considered separately, were non-significant ( $p=0.068$ and $p=0.104$; respectively). In the whole study group, PWD of at least $80 \mathrm{~ms}$ was observed in 14 patients (all with ASD). Six (42.9\%) of them had an AF episode after the procedure. On the other hand, only one (2.4\%) patient with lower PWD had AF after ASD closure. In the whole study group, PWD of at least 60 ms was observed in 57 patients; 33 (57.9\%) of them had SVEB after the procedure. Lower PWD was noted in 67 patients, and 23 (34.3\%) of them had at least one SVEB after the procedure.

\section{DISCUSSION}

In patients with ASC, abnormalities in intra- and interatrial conduction reflected by increased P-wave duration and its dispersion (dispersion of depolarisation/repolarisation) are observed [18]. PWD in ASD was predicted by RVOT proximal diameter and LA area, while in patients with PFO, besides RVOT proximal diameter and smoking, tricuspid insufficiency was also found to play an important role in PWD prediction.

Ndrepepa et al. [19] found that electrical activity obtained from surface ECG recordings correlates with conduction in certain parts of the atria, and this is not just the effect of different projections of the $\mathrm{P}$-wave vector, which result from difference in angles between it and ECG lead axis. Similarly to our observations, Yavuz et al. [20] noted increased maximum 

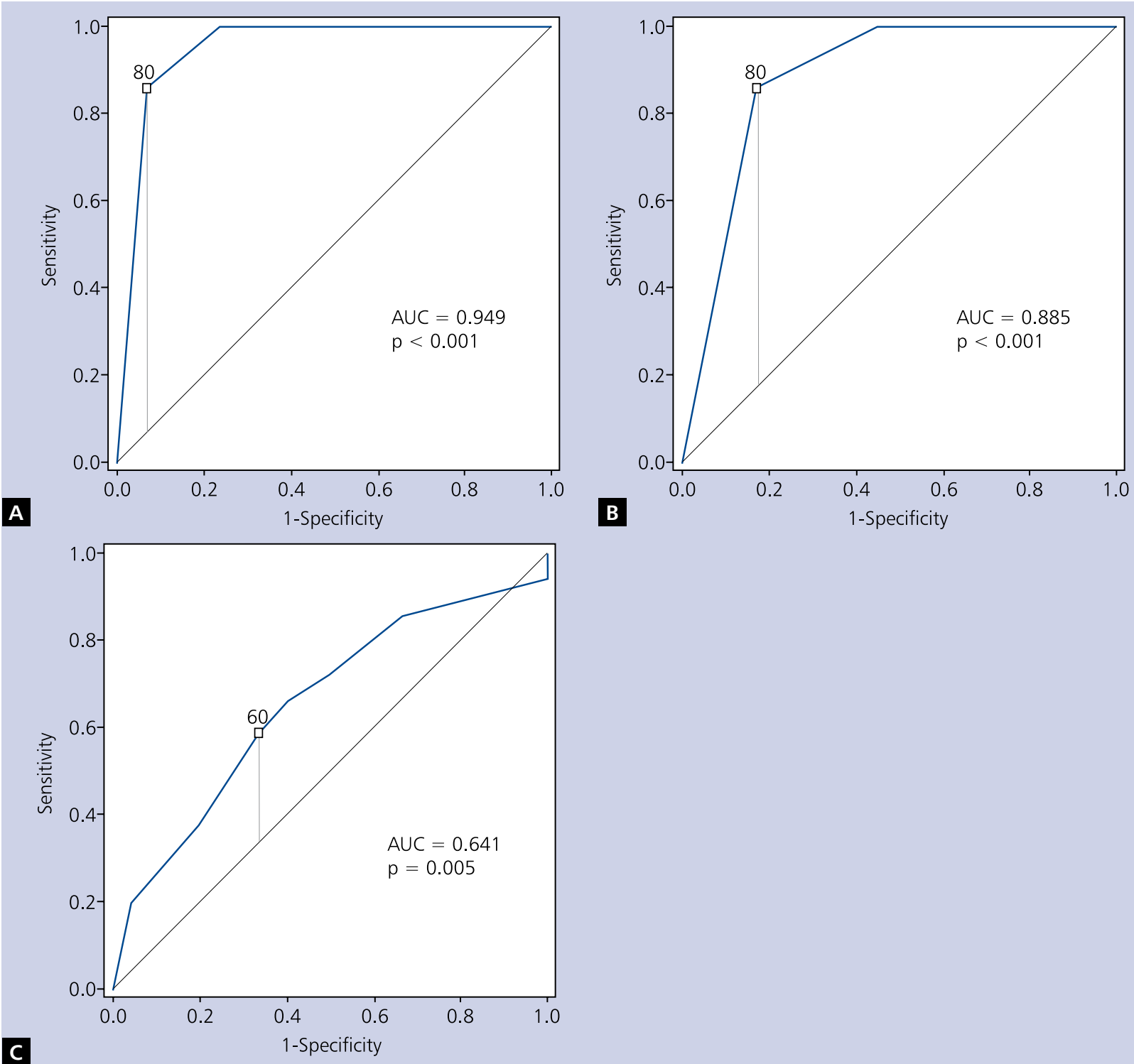

Figure 1. Receiver operating characteristic (ROC) curve for the determination of the cut-off point of P-wave dispersion before the procedure, for the presence of an atrial fibrillation episode six months after a successful closure of atrial septal communication (ASC) (A), and atrial septal defect considered separately (B). ROC curve for the determination of the cut-off point of P-wave dispersion before the procedure, for the presence of supraventricular extrasystolic beats six months after successful ASC closure (C); AUC - area under the curve. Positive thresholds were determined using the Youden index

P-wave duration and PWD in children with ASD, compared to controls, and observed maximum P-wave duration and PWD reduction within the first year after surgical ASD closure. Baspinar et al. [21] noted a decrease in PWD even one week after surgical (but not transcatheter) closure of secundum-type ASD. Lack of PWD reduction among children who underwent transcatheter closure could result at least in part from larger sizes of ASD in patients who underwent the surgical closure. Interestingly, at the same time, in the transcatheter ASD closure group of patients, a reduction of HR was observed [21].
On the other hand, immediately after ASD closure an increase in both maximum P-wave duration and PWD was noted, irrespective of the device used (Amplatzer vs. Figulla septal occluder) [22]. Our results underline the dynamics of myocardial remodelling after ASD closure.

Increased PWD (> $40 \mathrm{~ms}$ ) was reported to have a significant influence on the risk of AF development, both idiopathic and associated with diseases influencing cardiovascular function [23-25]. Numerous experimental and clinical studies have shown that AF/atrial flutter in heart defects (including 
heart defects with shunts) is caused by atrial wall remodelling, defined not only as the change in the size and shape, but also as the changes of structure and proportions between muscular and fibrotic tissue, along with changes in metabolism and myocyte electrophysiological properties. The persistence of arrhythmias, despite the closure of the defect, may be a consequence of permanent atrial remodelling resulting from long-term increase in intra-atrial pressure [5, 14]. Interestingly, in our group of patients who underwent percutaneous ASD closure, AF episodes six months after the procedure could be predicted by a PWD of at least $80 \mathrm{~ms}$.

Similar results with regards to PWD were observed in a smaller group of ASD patients and were associated with the lack of enlarged RA size normalisation three months after the procedure [26].

Atrial septal communication closure may be associated with complications [27-29]; however, closure of ASC with an occluder does not cause significant conduction disorders but transiently increases supraventricular heart rhythm disorders and leads to a significant increase in mean and maximal HR a month after the procedure $[5,14,18]$. It may be associated with procedure-related injuries, instrumentation during catheterisation, invasive measurement of the defect, and attempts of passing the catheter through the ASC. Previously, significant correlations were found between fluoroscopy time and occluder size, which reflect the procedure difficulty, and the number of SVEBs one month after the procedure [5, 14]. The more time is needed for proper occluder placement, the greater the probability of atrial wall and interatrial septum injury, which may induce supraventricular tachyarrhythmias. In our study, six months after the procedure, these abnormalities were absent. However, interestingly, both fluoroscopy time and radiation absorbed dose correlated with PWD and maximum P-wave duration.

At present, the predominant view is that in some patients closure of the defect may prevent recurrence of atrial arrhythmias and is associated with a reduced prevalence of arrhythmias [18]. In our study, the numbers of SVEBs and VEBs before the procedure were low (from a clinical point of view). However, it should not be expected that the correction of the defect would lead to sinus rhythm restoration in patients with chronic AF [30]. Our observations are consistent with the results obtained by other authors and highlight also the potential impact of smoking and hypoxaemia on PWD [31, 32].

Our study has several limitations. The assessment of PWD was performed manually. However, this method could be useful in clinical practice because it is easy to perform and seems reasonable in light of previous studies [10, 26]. Measurements of P-wave duration and dispersion were conducted according to generally accepted rules $[10,11,26]$. We did not assess inter- or intra-observer variability because our aim was not to set normal values for $\mathrm{P}$-wave duration and dispersion, but to investigate the role of PWD in the prediction of AF after percutaneous closure of ASC. Echocardiography and Holter ECG monitoring were performed only twice; more studies would provide more detailed dynamics of the observed changes. Moreover, prolonged ECG monitoring to detect and quantify atrial arrhythmias would be advantageous and could result in a higher number of patients with diagnosed $A F$ episodes during follow-up. Patients with ASD and PFO differ with regards to pathophysiology, symptomatology, natural history, and indications for the procedure.

In conclusion, in patients before ASC closure the most important factors influencing PWD are increased left atrial area, RVOT proximal diameter, presence of ASD, history of smoking, and paroxysmal dyspnoea. Percutaneous closure of ASC is associated with reduction of PWD and fewer episodes of arrhythmia six months after the procedure. PWD predicts AF episodes after ASD closure.

\section{Conflict of interest: none declared}

\section{References}

1. Martin SS, Shapiro EP, Mukherjee M. Atrial septal defects - clinical manifestations, echo assessment, and intervention. Clin Med Insights Cardiol. 2014; 8(Suppl 1): 93-98, doi: 10.4137/CMC. S15715, indexed in Pubmed: 25861226.

2. Hari P, Pai RG, Varadarajan P. Echocardiographic evaluation of patent foramen ovale and atrial septal defect. Echocardiography. 2015; 32 Suppl 2: S110-S124, doi: 10.1111/echo.12625, indexed in Pubmed: 24888883.

3. Rigatelli G, Aggio S, Cardaioli P, et al. Left atrial dysfunction in patients with patent foramen ovale and atrial septal aneurysm: an alternative concurrent mechanism for arterial embolism? JACC Cardiovasc Interv. 2009; 2(7): 655-662, doi: 10.1016/j. jcin.2009.05.010, indexed in Pubmed: 19628189.

4. Komar M, Podolec P, Przewłocki T, et al. Transoesophageal echocardiography can help distinguish between patients with "symptomatic" and "asymptomatic" patent foramen ovale. Kardiol Pol. 2012; 70(12): 1258-1263, indexed in Pubmed: 23264244.

5. Pieculewicz M, Podolec P, Przewłocki T, et al. [Conduction abnormalities and arrhythmias after transcatheter closure of atrial septal defect with the Amplatzer Septal Occluder]. Postepy Kardiol Interwencyjnej. 2006; 3(5): 207-213.

6. Baspinar O, Kervancioglu M, Koruk S, et al. Follow-up of $P$ dispersion after transcatheter closure of an atrial septal defect in children. J Pak Med Assoc. 2014; 64(5): 546-548, indexed in Pubmed: 25272541.

7. Thilén U, Carlson J, Platonov PG, et al. Prolonged P wave duration in adults with secundum atrial septal defect: a marker of delayed conduction rather than increased atrial size? Europace. 2007; 9 Suppl 6: vi105-vi108, doi: 10.1093/europace/eum214, indexed in Pubmed: 17959685.

8. Janion M, Kurzawski J, Sielski J, et al. Dispersion of P wave duration and $\mathrm{P}$ wave vector in patients with atrial septal aneurysm. Europace. 2007; 9(7): 471-474, doi: 10.1093/europace/eum089, indexed in Pubmed: 17540665.

9. Dilaveris PE, Stefanadis CIP. Wave dispersion: a valuable non-invasive marker of vulnerability to atrial arrhythmias. Hosp Chron. 2006; 1(3): 130-137.

10. Lelakowska-Pieła M, Pudło J, Engel A, et al. [Analysis of $\mathrm{P}$ wave duration and dispersion in paroxysmal atrial fibrillation]. Pol Merkur Lekarski. 2013; 35(209): 259-262, indexed in Pubmed: 24575644.

11. Dursun H, Tanriverdi Z, Colluoglu T, et al. Effect of transcatheter aortic valve replacement on P-wave duration, P-wave dispersion and left atrial size. J Geriatr Cardiol. 2015; 12(6): 613-617, doi: 10.11909/j.issn.1671-5411.2015.06.016, indexed in Pubmed: 26788037. 
12. Zimetbaum $P$, Goldman A. Ambulatory arrhythmia monitoring: choosing the right device. Circulation. 2010; 122(16): 1629-1636, doi: 10.1161/CIRCULATIONAHA.109.925610, indexed in Pubmed: 20956237.

13. Liao J, Khalid Z, Scallan C, et al. Noninvasive cardiac monitoring for detecting paroxysmal atrial fibrillation or flutter after acute ischemic stroke: a systematic review. Stroke. 2007; 38(11): 2935-2940, doi: 10.1161/STROKEAHA.106.478685, indexed in Pubmed: 17901394.

14. Komar M, Przewłocki T, Olszowska M, et al. Conduction Abnormality and Arrhythmia After Transcatheter Closure of Atrial Septal Defect. Circ J. 2014; 78(10): 2415-2421, indexed in Pubmed: 25152421

15. Pepi M, Evangelista A, Nihoyannopoulos P, et al. European Association of Echocardiography. Recommendations for echocardiography use in the diagnosis and management of cardiac sources of embolism: European Association of Echocardiography (EAE) (a registered branch of the ESC). Eur J Echocardiogr. 2010; 11(6): 461-476, doi: 10.1093/ejechocard/jeq045, indexed in Pubmed: 20702884.

16. Błażejewski J, Sinkiewicz W. [Echocardiographic assessment of the right heart -2015 expert guidelines in clinical practice]. Folia Cardiol. 2017; 12(2): 171-178.

17. Rudski L, Lai W, Afilalo J, et al. Guidelines for the Echocardiographic Assessment of the Right Heart in Adults: A Report from the American Society of Echocardiography. J Am Soc Echocardiogr. 2010; 23(7): 685-713, doi: 10.1016/j.echo.2010.05.010.

18. Mostafa S, Abdelhakim A, Aboelazm T, et al. Effect of transcatheter closure of secundum atrial septal defect on cardiac electric remodeling. Int J Heart Rhythm. 2017; 2(1): 40, doi: 10.4103/23524197.208453.

19. Ndrepepa G, Zrenner B, Deisenhofer I, et al. Relationship between surface electrocardiogram characteristics and endocardial activation sequence in patients with typical atrial flutter. Z Kardiol. 2000; 89(6): 527-537, indexed in Pubmed: 10929438.

20. Yavuz T, Nisli K, Oner N, et al. The effects of surgical repair on $\mathrm{P}$-wave dispersion in children with secundum atrial septal defect. Adv Ther. 2008; 25(8): 795-800, doi: 10.1007/s12325-008-0081-3, indexed in Pubmed: 18670742.

21. Baspinar O, Sucu M, Koruk S, et al. P-wave dispersion between transcatheter and surgical closure of secundum-type atrial septal defect in childhood. Cardiol Young. 2011; 21(1): 15-18, doi: 10.1017/S1047951110001307, indexed in Pubmed: 20920379.
22. Paç FA, Balli S, Topaloğlu S, et al. Analysis of maximum P-wave duration and dispersion after percutaneous closure of atrial septal defects: comparison of two septal occluders. Anadolu Kardiyol Derg. 2012; 12(3): 249-254, doi: 10.5152/akd.2012.069, indexed in Pubmed: 22381925.

23. Lelakowski J, Majewski J, Czunko A. [The influence of pacing mode (VDD, VVI) on P wave dispersion]. Folia Cardiol. 2001; 8: 651-657.

24. Karabag T, Aydin M, Dogan SM, et al. Prolonged P wave dispersion in pre-diabetic patients. Kardiol Pol. 2011; 69(6): 566-571, indexed in Pubmed: 21678292.

25. Tacoy G, Akboga MK, Yayla C, et al. The effect of statin treatment on P-wave characteristics and atrial conduction time. Kardiol Pol. 2015; 73(9): 747-452, doi: 10.5603/KP.a2015.0090, indexed in Pubmed: 25985732.

26. Fang F, Luo XX, Lin QS, et al. Characterization of mid-term atrial geometrical and electrical remodeling following device closure of atrial septal defects in adults. Int J Cardiol. 2013; 168(1): 467-471, doi: 10.1016/j.ijcard.2012.09.119, indexed in Pubmed: 23063142.

27. Gutiérrez-Barrios A, Lacal-Peña JM, Vignau-Cano JM, et al. Silent early migration of a Figulla ${ }^{\circledR}$ septal occluder into the left ventricle. Kardiol Pol. 2017; 75(7): 724, doi: 10.5603/KP.2017.0130, indexed in Pubmed: 28703271.

28. Cottini M, Pergolini A, Musumeci F. Atrial septal defect occluder dislocation engaged through the tricuspid valve: surgical removal via right thoracotomy. Kardiol Pol. 2017; 75(3): 279, doi: 10.5603/KP.2017.0052, indexed in Pubmed: 28326527.

29. Goreczny S, Bedair R, Bilska K, et al. Retrieving a large embolised atrial septal occluder - hooked... and landed. Kardiol Pol. 2017; 75(3): 277, doi: 10.5603/KP.2017.0050, indexed in Pubmed: 28326525.

30. Blake GE, Lakkireddy D. Atrial septal defect and atrial fibrillation: the known and unknown. J Atr Fibrillation. 2008; 1(3): 45, doi: 10.4022/jafib.45, indexed in Pubmed: 28496588.

31. Akturk E, Yağmur J, Açıkgöz N, et al. Assessment of atrial conduction time by tissue Doppler echocardiography and P-wave dispersion in smokers. J Interv Card Electrophysiol. 2012; 34(3): 247-253, doi: 10.1007/s10840-011-9658-x, indexed in Pubmed: 22391961.

32. Yagmur J, Yetkin O, Cansel M, et al. Assessment of atrial electromechanical delay and influential factors in patients with obstructive sleep apnea. Sleep Breath. 2012; 16(1): 83-88, doi: 10.1007/s11325-010-0477-6, indexed in Pubmed: 21221821.

Cite this article as: Lelakowska M, Komar M, Matusik PT, et al. Transcatheter closure of atrial septal communication: impact on P-wave dispersion, duration, and arrhythmia in mid-term follow-up. Kardiol Pol. 2018; 76(10): 1465-1473, doi: 10.5603/KP.a2018.0149.

\section{WHAT IS NEW?}

Our study showed that P-wave dispersion before percutaneous atrial septal communication closure was predicted by proximal right ventricular outflow tract diameter, left atrial area, atrial septal defect, smoking, and paroxysmal dyspnoea.

Six months after a successful closure of atrial septal communication, a reduction in P-wave dispersion was observed in the whole group of patients as well as in patients with atrial septal defect and patent foramen ovale considered separately. Moreover, a reduction in the number of supraventricular and ventricular extrasystolic beats and fewer atrial fibrillation episodes six months after atrial septal communication closure were also observed.

P-wave dispersion of $80 \mathrm{~ms}$ predicts postprocedural atrial fibrillation episodes in patients with atrial septal defect. 